\title{
Addicted to Proof
}

\section{Peter Shor}

He is quite famous; at forty, he discovered

A law for the distribution of the size

Of gaps between consecutive prime numbers,

And for this work, he won the Abel Prize.

He teaches well-the students love his classes;

His mind seems sound, despite his advanced years,

But somehow, his ability in math has,

In the course of time, completely disappeared.

So all his friends try to dissuade him gently

From announcing he has proved Goldbach was right;

His colleagues listen to his talk intently,

And laugh at him when he is out of sight.

For the fact is that proof is an addiction,

And it doesn't matter if you're right or wrong;

What matters is the absolute conviction

That you've found something no one has ever known.

\section{Notes}

The basic idea originally came from my realizing that the thrill of discovery is just as exciting with an incorrect proof as with a correct one, and wondering whether this is what motivates some of the cranks who send mathematicians their proofs of the Riemann hypothesis, $\mathrm{P} \neq \mathrm{NP}$, the continuum hypothesis, and so forth. The thrill of discovery is one of the things that motivates me, so if I ever start acting this way, please accept this poem as my apology in advance.

On reading this poem, you may believe that you can identify the person who inspired it. However, you are likely to be only partly right-I had more than one person in mind when I wrote it.

Peter Shor

Massachusetts Institute of Technology

Cambridge, MA 02139

USA

e-mail: shor@math.mit.edu

Publisher's Note Springer Nature remains neutral with regard to jurisdictional claims in published maps and institutional affiliations. 